\title{
The Effect of General and Specific Topics on Writing Performance of EFL students
}

\author{
Hussein Meihami ${ }^{1, *}$, Bahram Meihami ${ }^{2}$ \\ 1Department of English Language Teaching, Ghorveh Branch, Islamic Azad University, Ghorveh, Iran \\ 2Department of Accounting, Ghorveh Branch, Islamic Azad University, Ghorveh, Ir
}

*E-mail address: hussein.meihami99@gmail.com

\begin{abstract}
ABSTERACT
This paper describes a study exploring the effect of topical $\mathrm{k}$ vedge on in performance of EFL students. A total of 158 accounting students of Islamic A7 d U rsity of $\mathrm{H}_{\hat{c}}$ sedan Branch in two levels of proficiency, intermediate and advanced, particip a n this $\mathrm{y}$. They were voluntarily participated in an English Learning Program provided by Jiami Azad Un 1 ty. At the end of the program, each student was required to write two essays: or that requires general knowledge of students about their opinion on continuing their education in uni sity and the ther that requires them to use their specific knowledge and write about preparing of $b$ ce sheet accounting. After the results were manifested, writing on the specific topic yielded lowe weak idea development and concluding paragrat his researcn there was an interview with students to figure out about their opinion of these two pr npts dents participated in this interview who were all agree that the prompt that required them ase specific knowledge of their major was much more challenging than the general pr This res rch results show the importance of preparing and developing appropriate prompts fo EFL iting test
\end{abstract}

Keywords: Topical knowled se, rith. Till; general topic; specific knowledge

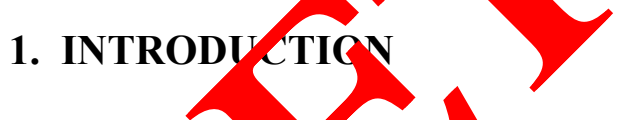

There is owing ebate on the choosing of the effective writing topic on writing assess this tor toal knowledge causes this controversial subject to be wider. Carlson and Birdg, (1986) ated that "the content implied by the topic must be as fair as possible, not cu cific set of personal or cultural experiences" (p. 139). This statement is to some e. d straightforward with regard to the importance of topic as a variable that potentially influence writing. As He and Shi (2012) stated "topic assigned in an essay test demand particular attention because they initiate and direct the act of writing that produce sample for evaluation." In the context of the classroom, there is always students complaining about the subjects, topics, or prompts in the writing classrooms. These complaints baffled writing teachers on how to select a prompt in their writing classroom that students be able to write about it. In this case this quantitative- qualitative research is going to explore its investigation on the relationship between two different types of topics: general topic in which general knowledge is necessary and specific topic in which some specific aspects of knowledge in a 
specific field is necessary. This study explores the writing performance of 158 accounting students; both have knowledge about accounting and general view of general topic.

\section{1. Review of Literature}

According to Bachman and Palmer (1996) "only will the interaction of one's prior knowledge can we make inference about the language ability of the test takers". This statement is quite in the same pave with what Alexander and Schallert (1991) defined as topical knowledge "the interaction between ones prior knowledge and the content of specific passage". The main point in the statements of these scholars is that it is to a great extent to evaluate ones language proficiency based on the test that belongs to a specific cul are, conto or topical contents.

In 1982, Winfield and Barnes conducted a study on comparing the fect yltural y familiar and unfamiliar material on the writing of students from interm diate vel in $\mathrm{SL}$ classes. In that study half of participants were Spanish speaking and 5 we cring do ferent language backgrounds. Before starting to write, two thematic sag vere re $\mathrm{d}$ by the participants; one all about Spanish language in which students greater $\mathrm{h}$ vloge and one about Japanese language in which participants had very itt nowledge The provided materials, then, were taken away and students were requ to wh about what they learnt from the materials. In a comparison with the non-na ve speaker, na speaker of Spanish writings were much more fluent and with fewer ammatical errors. The findings of this research indicated that topic familiarity will increase e ability of performing on writing tests.

In another research, Tedick (1990) had an estigati $n$ on the effect of topical knowledge that focused on subject matter as. He com students written essays with writing on a general and a field - related to los. narticipants of the study were graduate students enrolled in composition courses at $\mathrm{di}^{\prime}$ eren, levels: beginning, intermediate, and advanced in a university ESL pro The it estigation showed that all proficiency levels yielded significantly better pe orma e on w ing in field specific topics. According to

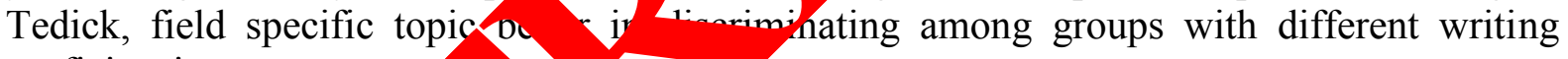
proficiencies.

In 2007, Lee and derson lik dick did their investigation on a gradate group who possessed topical k- wle based o. their major. They investigated topic generality of a writing placemen sts by ro $n g$ three subject specific topics integrated with listening and reading source. In $t^{1}$ is continuo study, over six years the writing performance of the students was recorda to 1 von ast with that of Tedick, subject specific did not favour test takers with matching a rtment affiliation. On this account, the probability of getting lower scores decre write ro aciency level increase, so it was suggested that general knowledge of lap age c mpetenc might have played a more significant role than topical knowledge in the integ cest involved reading and writing.

F 2003) who focused on test takers' point of view, He and Shi (2008) compared ESL students' ceptions and experiences of two standardized English writing tests: the Test of Written English (TWE) in TOEFL and the essay task in the LPI. In western Canada, the TWE is used as a university entrance test for international students who speak English as a second or foreign language, whereas the LPI is required, in many post-secondary institutions, for these students to register for the compulsory first-year English courses. As international students, all participants in the study had passed the TWE but many had taken the LPI repeatedly before passing it. All participants complained about the cultural bias of essay prompts or topics in the LPI such as 'Road rage in Vancouver,' 'Pride of being a Canadian citizen' and 'Divorce rate in North America.' These complaints raised questions about the validity of the test. The 
researchers called for further investigations to address issues of fairness and equity in L2 writing assessment.

He and Shi (2012) conducted a research on the importance of topical or prior knowledge in ESL writing. Conducted in a Canadian college, the study involved 50 ESL students across three English proficiency levels. The students responded to two sample prompts of the LPI, a standardized English proficiency test with an impromptu essay task. One prompt required general knowledge about university studies, and the other required specific knowledge about federal politics. Since students' perceptions of task difficulty may help explain their task performances (Robinson, 2001), they conducted follow-up interviews to explore ctudents' perceptions of their writing experiences with the two prompts.

This research aims to add to remove some of the previously conducted earch and explore how topical knowledge can have effect on the writing performance an EF context. In this regard, we are investigating two levels of proficien $y$, intermo te and advanced. This study is going to investigate the following questions:

1. Do EFL students across different proficiency levels per a rently term of overall and component scores when regarding the prom requiring $1 \mathrm{er}$ and on the other side prompts that require specific knowledge?

2. What are the participants' ideas and perceptions to different prompts?

\section{METHOD}

\section{1. Participant}

A total of 158 EFL students of Azad Un va Ranch of Hamedan, all male and ranging in age from 18 to 23 years participated in this xp crimy al study. It should be stated that they are all originally Iranian and Persia and participated in an English I arnin Progran that was provided by the university for them. In their specific majors, the in voluntary participate in witing fill traming program at Azad University. Prior to this program a test had bee Ken amons $1 /$ students and according to result 78 students ranked as low advanced EF wri 90 studen $\iota$ ranked at intermediate levels and others ranked as in beginner level of frciency. $\mathrm{e}$ to the purpose of this research we decided to just investigate on advanced ad intrmediate adents. These participants divided into 6 classes in each of them teach ork on bo theneral topics and specific ones while they were working with students' writin. The pro sram took two months, in which student participated in 16 sessions.

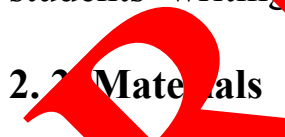

2. 2.

Prio. The final test of writing in the program, a pilot study was conducted to define two types of prompts that require different type topical knowledge. A group of 20 students participated in the pilot study. They were given 30 topics. They were asked to select the easiest and the hardest topics. The results indicated that $94 \%$ of participants agreed that writing about continuing higher education in the university as an easy prompt to write about. On the other hand, $98 \%$ of the participants selected writing about balance sheet as a tough to write about.

Prompt A: What's your consideration about continuing your higher education in the University 
Prompt B: As a student of BA in Accounting, write about how is preparing a balance sheet.

This two prompts were administrated in the final exam. It should be stated that there were two sessions for exam, in one, students wrote about the general prompt and in the other one they wrote about the specific prompts. In order for encouraging students to write as much as they can there was no time limitation in the exam.

\section{2. 2. Scoring Procedure}

This paper followed its scoring procedure of what He and Shi used. We extrac ble of six point rating scale which was analytic from their research. The componen $s$ of the ta as you can see in table 1 are content, organization, and language.

Table 1. Six-point analytic rating scale (Extracted from He and shi 20?2).

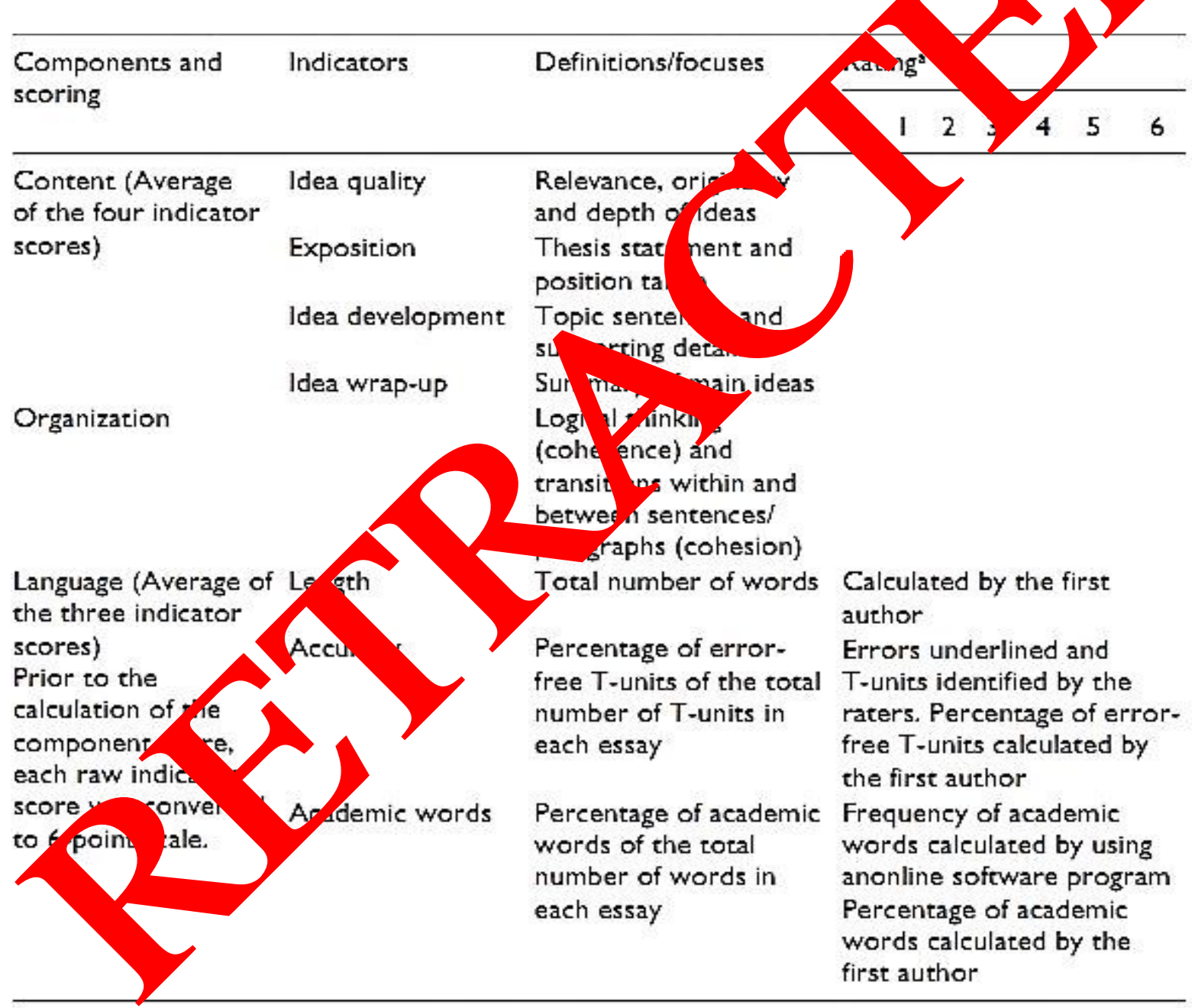

Note: ${ }^{0} 0$ =Cannot be evaluated; 1 = No proficiency: 2 = Minimal; 3 = Developing: 4 = Adequate; 5 = Effective: 6 = Advanced.

This rating scale had six levels from the lowest 0 to the highest 6 . Four nonnative writing teacher were required to rate these essays. Pearson Correlation Coefficient of the four teachers were higher than $.83(\mathrm{r}>.83)$ about .86 . 


\section{2. 3. Test}

SPSS version 16 had been used in order to increase the analysis accuracy. Three main tests had been conducted in this investigation. First descriptive statistics were drawn, then a pair sample t-test was conducted to find out about the students over all writing scores on the two prompts across different proficiency levels, and finally a series of $3 \times 2$ ANOVA were conducted to identified the main effects and interactions of two proficiency levels and two prompts on the writing performance.

\section{2. 4. Interview}

In order to verify the quantitative finding based on the writing scores, ar nterview $\mathrm{h}$ been held with 12 participants. They were asked to speak about 10 minutes abou ir writir experience in both the general prompts and the specific one. It was interestis that 0 participants confessed that writing about preparing Balance Sheet as tren ndous nard although they had lots of study about that in their courses. On the th all 1 students agreed that writing about general topic was much easier even lough th vrote about this prompt for the first time.

\section{3. Procedure}

Azad university branch of Hamedan had an En lish Language Learning Program for the students of $4^{\text {th }}, 5$ th, 6 th, semester in all majors. In w er of 2013, he university had registered students to participate in this program. After the firs ase had done, students went through proficiency test to be ranked as different ler of profic. In this case, the proficiency test was a moderated version of IELTS test. Afte thr $1 \mathrm{t}$ made the students level of proficiency known, students were placed in the different ar es. his program students worked on the four different skills of language 1 ing: Sp king, Listening, Reading, and Writing. The teachers who were responsible $f$ r teac $\mathrm{ng}$ in th program were all nonnative yet experienced.

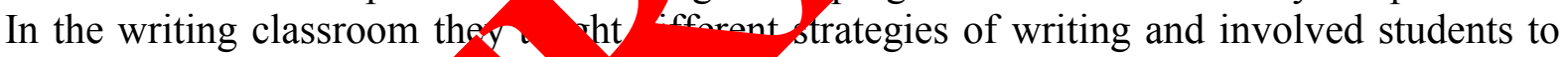
write about specific and genoal py pts. Sudents were required to mail their essays to their teachers to do correctio d to give ments on their writings. To some great extent, it was like portfolio writing in w student got not only corrective feedback from their teacher but also mark for wh hey wrot the final of the program, students had two tests one in which they were regr red to write aboy a general prompt:

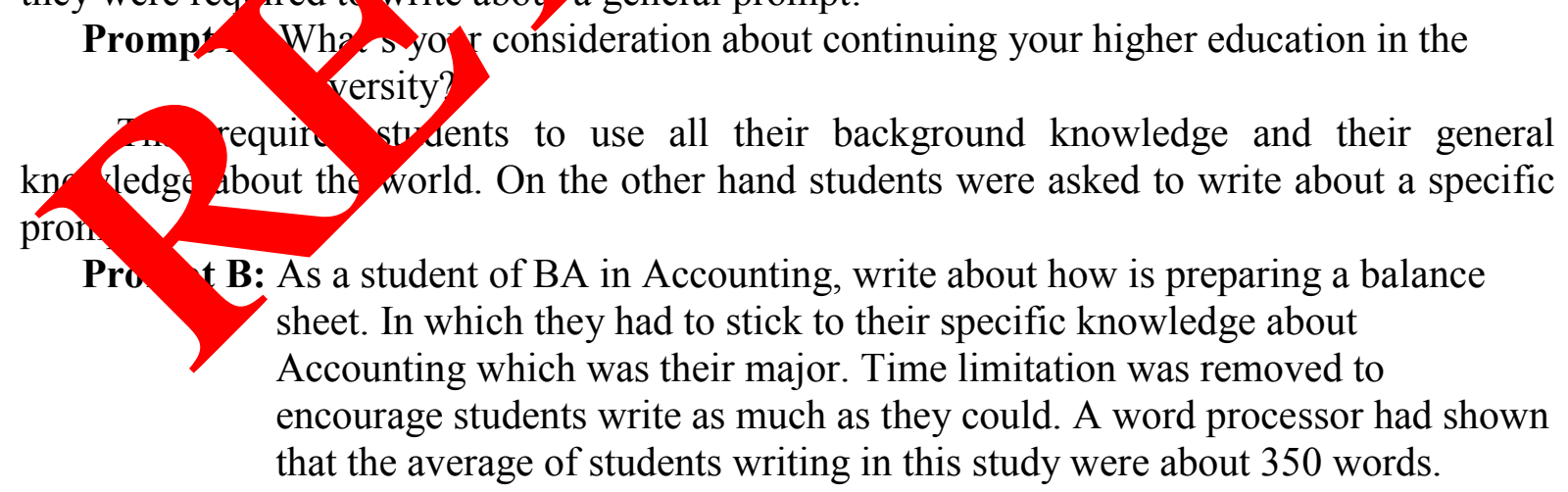

\section{RESULT}

Students across both groups of proficiency showed higher overall writing scores for the Prompt A in which they should write about a general topic than the other prompt in which they wrote about a specific topic which required them to use specific knowledge. The mean score 
for Prompt A in intermediate and advanced participants was 1.24 and 3.95 respectively in comparison with Prompt B in those levels of proficiency which was 0.52 and 3.01 respectively. The comparison shows that students have a better performance in writings which required general knowledge of students. Table 2 illustrates Descriptive statistics.

Table 2. Descriptive Statistics of Both Prompts in different Proficiency levels.

\begin{tabular}{cccccc}
\hline $\begin{array}{c}\text { Proficiency } \\
\text { Level }\end{array}$ & N & \multicolumn{2}{c}{ Prompt A } & Prompt B \\
\hline Intermediate & 80 & 1.24 & 0.53 & 0.52 & 0 \\
Advanced & 78 & 3.95 & 0.34 & 3.01 & 1.02 \\
All 2 Levels & 158 & 2.59 & 0.43 & & \\
\hline
\end{tabular}

The overall mean score is another proof for straents better p ormance on the first Prompt. For Prompt A it is 2.59 while the amount for rompt B is 1.76. This shows that students in the both proficiency levels did better in their writir when the re uired knowledge is general.

On the other hand, the results of the $3 \times 2$ rariate NOVA showed statistically significant main effects for proficiency leve $(\mathrm{F}(2,45)=, \mathrm{p}<.05)$ and prompt type $(\mathrm{F}(1$, $45)=124.24, p<.05)$, as well as a signific its action across different proficiency levels $(\mathrm{F}(2,47)=5.47, \mathrm{p}>.05)$ (Table 4). A post o Tun $\mathrm{b}$ analysis detected main effects of prompts on the overall writing scor all pa wise comparisons across proficiency levels (p $<.05)$. These findings indicate $\mathrm{a}$ asso tion bet topical knowledge and L2 writing across all proficiency levels. Table $\zeta$

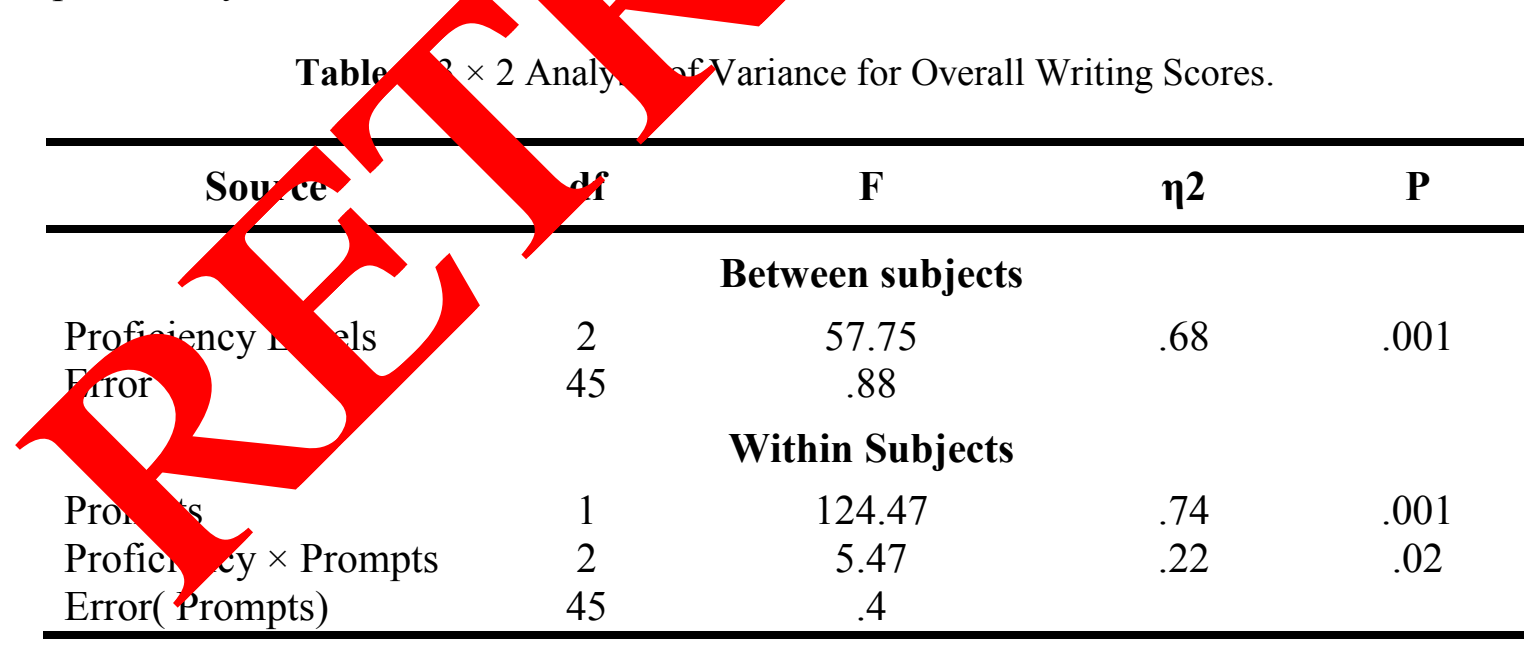

Table 4 shows the summary of component scores across different level of proficiencies. 
Table 4. Summary of Component Scores.

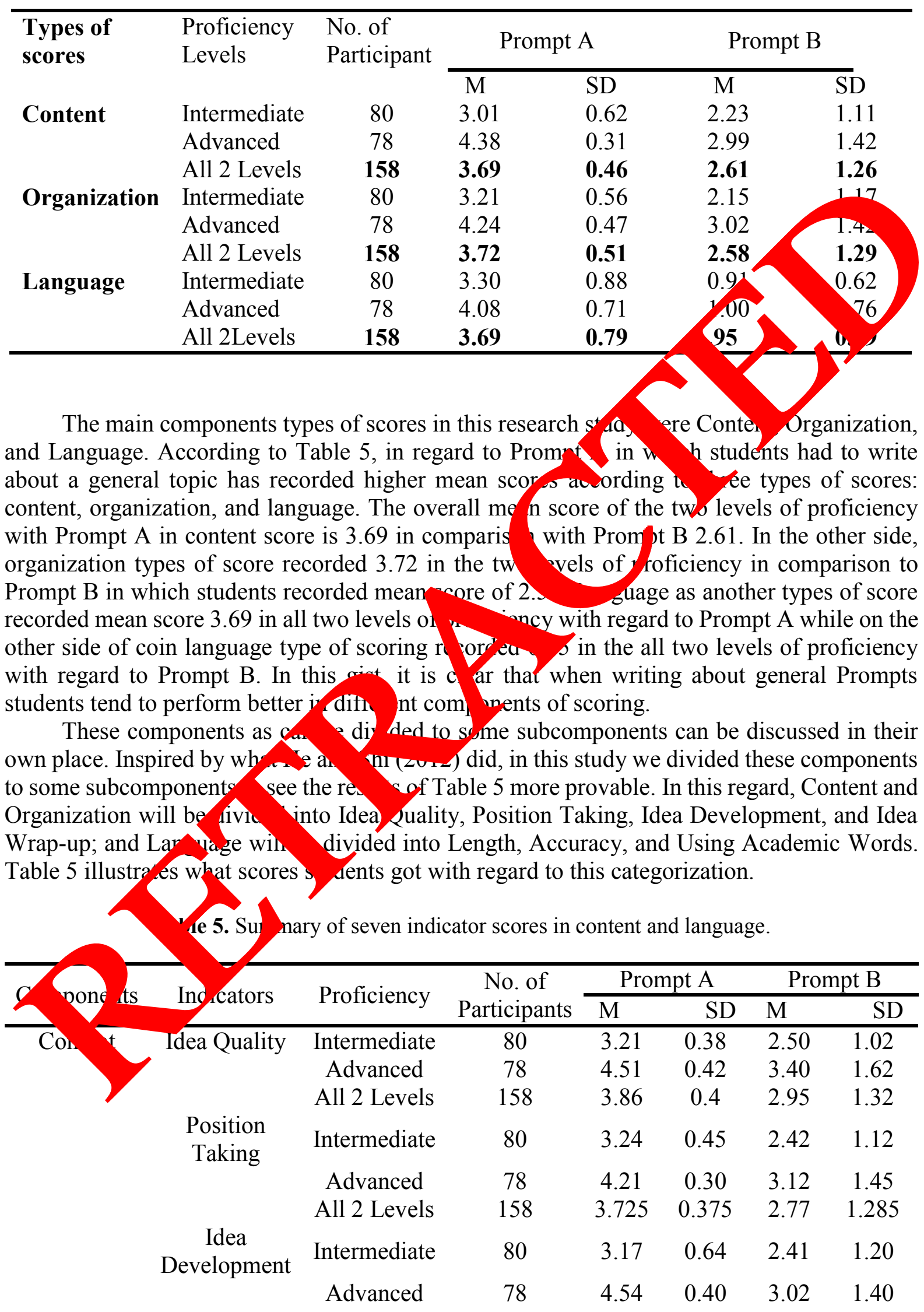




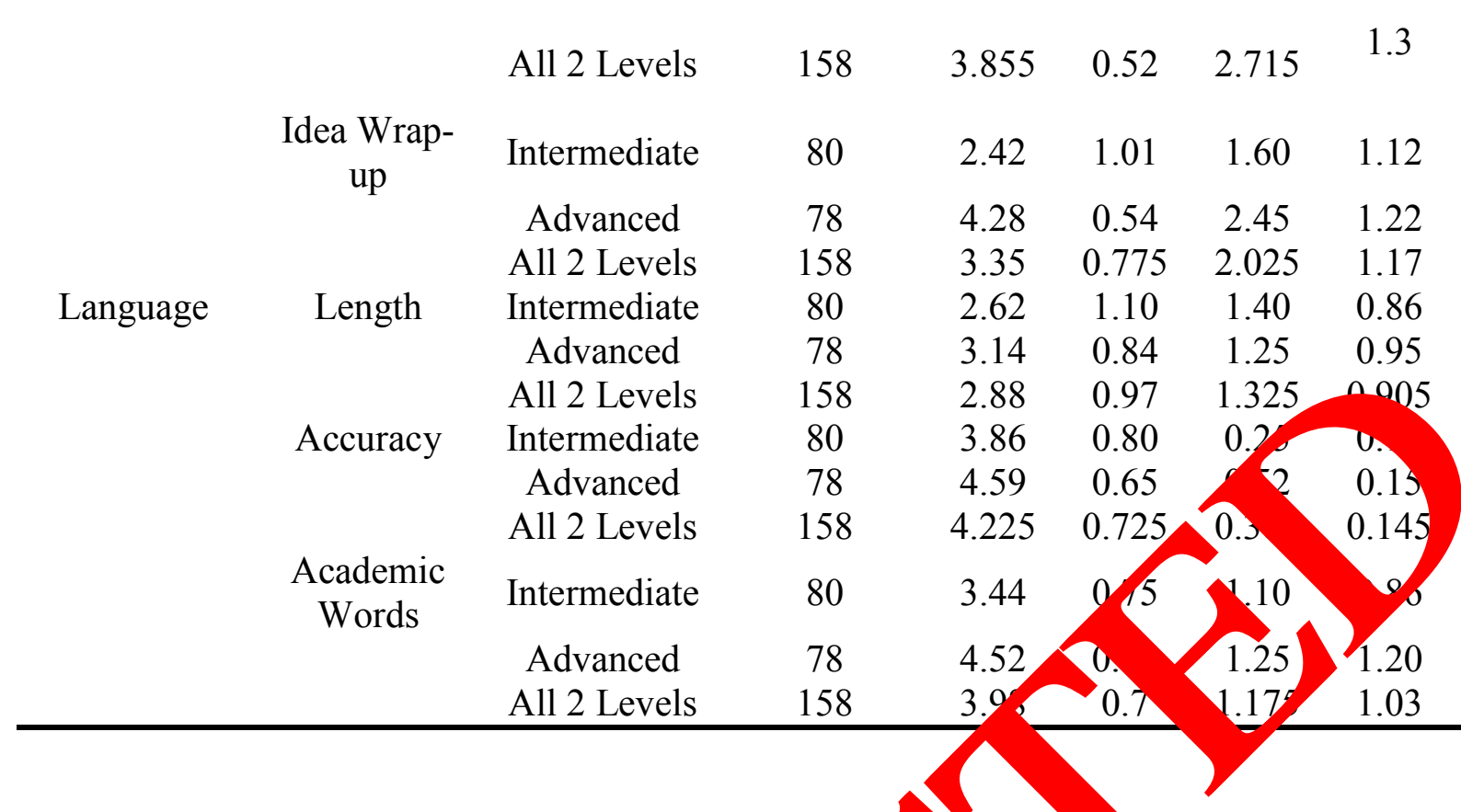

Table 5 is quite comprehensive with regard to aregorization oferent components. As the figures in the table illustrate, the All 2 Levels which is the sum of each subcomponent in a component, for the Prompt $\mathrm{A}$ is more than thes omponents for the Prompt $\mathrm{B}$. Now, one can consider that while writing in general topics, tents has better performance in their writing based on Content, Organization, an Language.

The first question of this research wa levels perform differently in term of overall an $1 \mathrm{ce} n \mathrm{py}$ it scores when regarding the prompts requiring general and on the other a-de promp that require specific knowledge?" that based on the obtained results we can s y tha tudents fEFL context who are across different level of proficiency do better on the mp that reoares their general knowledge about the topic. This better performance e bo regaru overall score and when it is considered with component scores.

\section{1. Students' $P$ cetion}

The se ond re earch que,tion was "What are the participants' ideas and perceptions toward the th diff crent fompts?" for answering this research question after the final test, there wasan into sw on $10 \mathrm{w}$ students feel about the two prompts. They were asked to declare their atlu s abou feeling about their writing event. All 24 students said that Prompt A w rite asy for tem when they wrote about it and at the moment of writing about this prom nought about their neatness of their writing and not what is the topic. They stated th they thought they had good bunch of knowledge about Prompt A and they didn't have any a ise of uneasiness in the test time. On the other hand they all had the feeling of confusion when they were asked how was the other prompt (Prompt B) for you. Again all 24 students declared that it was quite tough and they had the feeling of uneasiness toward the topic.

Among their takings it was concluded that at the moment of writing time they just thought about the topic and what is it all about and not about the writing components such as Content, Language, and Organization. One of them asserted that when the test was administered I thought that it is going with our courses in Accounting and for several minutes I just backed all those units I studied about preparing Balance Sheet, but unfortunately there 
were no release in my mind. The other said that although we are the students of accounting it is not fair to write about the components of it because we are not the master of all part of it. The results of students' interview cleared this fact that the most important barrier for them in writing about the specific topic was their lack of knowledge in that matter.

Among their takings something else could be found. They said that they didn't have the needed vocabulary to use in their writing. Vocabulary as an important component of language learning in general and language writing in particular should be learnt in the first to help further improvement in language learning skills. It is logical that even if a person has some good ideas about a topic but does not have the necessary vocabularies to elaborate those good idno the phenomena of writing will be due to nothing. It can be mention that EFL student in din majors just study the very beginning stage of their major in second languar and it is is enough to formulate a writing text about it.

\section{CONCLUSION}

The results of the present study confirm that students writing in which they are required the general knowledo thus porting the findings of previously conducted research (He and Shi, 2012; W; and Ba Felfeli, 1982; Fox, 2003; Fox, Graves, \& Shohamy, 1999). According to he findings of this research students who were studying Accounting as a university major di better in the general prompt which was about their consideration of continuing higher edu ton than the other Prompt in which students were asked to write about the prepraing Balan

As He and Shi stated(2012) when a pr stouired students to challenge with specific knowledge "reflects construct-irrelevant var bil" $y$ nallenging L2 writers with a topical knowledge that they did not posseca and, the eby, causing notably lower scores across all proficiency levels than on the ge era $\mathrm{k}$ which rave them greater opportunity to display their ability". In this regard, studep rere bliged to consider more about the topic and its aspects and not the writing itself, s co con writing with regard to three main components: Content, Organization, Languag ould drop.

It is important no hat the fin rngs of this study are in accordance with EFL context in which students ro for th urpose of foreign language and not second language. The other matter is in this study we condu $d$ our test on two advanced and intermediate level so further research sho be do to thee the effect of topical knowledge on basic level of proficiency.

The peda cal imp cation of the findings of this research for language test planners is that wh hey an unce a topic to gouge students writing ability proficiency, they have to con der th essence the topic in order not to leave students with the confusing of topic.

Ackno Tgement

This ady got its procedure from what had conducted by He and Shi (2012) and in this regard thank them and consider all their valuable contribution as conducive for conducting this paper in an EFL context. 


\section{References}

[1] Alexander P. A., Schallert D. L., Hare V. C., Review of Educational Research 61 (1991) 315-343.

[2] Artemeva N., Fox J., Journal of Business and Technical Communication 24 (2010) 476-515.

[3] Bachman L., Palmer A. (1996). Language testing in practice: Designing and developing useful language tests. Oxford: Oxford University Press.

[4] Fox J., International Journal of Testing 3 (2003) 21-48.

[5] He L., Shi L., Assessing Writing 13 (2008) 130-149.

[6] He L., Shi L., Language Testing 29(3) (2012) 443-464.

[7] Monirosadat Hosseini, et al., International Letters of Social and ani iic Sc nces 6 (2013) $1-12$

[8] Hussein Meihami, International Letters of Social and Hy ra tic Sciency (2013) $8-23$. [9] Hussein Meihami, International Letters of Social ind Humanistic , Cences 8 (2013)
24-33.

[10] Hussein Meihami, Bahram Meihami, Zeinab V aghani, I lternational Letters of Social and Humanistic Sciences 8 (2013) 57-65.

[11] Lee H. (2004). Constructing a field-spe thu thest for an ESL placemen procedure. Unpublished doctoral dissert io , Ony ersity of Illinois at Urbana-Champaign.

[12] Robinson P., Applied Lir istics 2 (2001) 27-57.

[13] Shi L., Language Te arro 18 vo1) sus-325.

[14] Spaan M. (1993 effect of p apt in essay examinations. In D. Douglas \& C. Chapelle (Eds. A ne lecade of language testing research: Selected papers from the 1990 Lang age Testing arch Colloquium (pp. 98-122). Alexandria, VA: Teachers of Engl sh to $S$ eakers of J ther Languages

[15] Tedick D. English or Specific Purposes 9 (1990) 123-143.

[16] $\mathrm{Nm}$ ld F. B nes-Felfeli W., Modern Language Journal 66 (1982) 373-378.

( Received 02 November 2013; accepted 07 November 2013 ) 